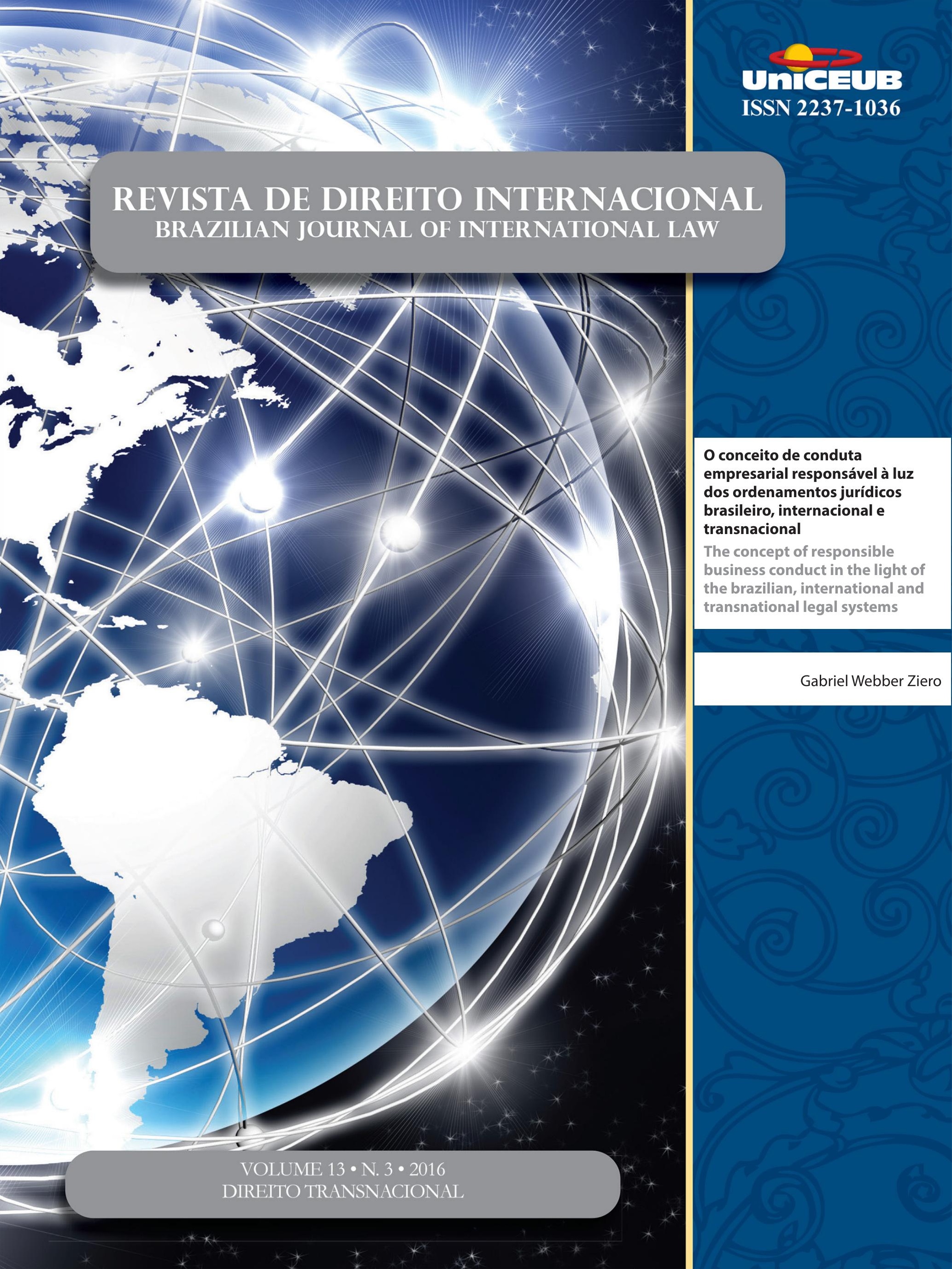


Crônicas da ATUALIdAde do direito internacional .................................................. 2

I. Dossiê Temático: Direito Transnacional .........................................................15

EDITORIAL: O Direito Transnacional - Circulação de normas e relações jurídicas transnacionais .......16 Priscila Pereira de Andrade

A emergênCia do direito transnacional ambiental .............................................18 Priscila Pereira de Andrade

Desafíos y RESPUESTAS TRANSNACIONALES FRENTE A LOS CRÍMENES AMBIENTALES ...............30 Rosmerlin Estupiñan-Silva

DiREITO TRANSNACIONAL E MUdANÇAS CLIMÁTICAS .50 Géraud de Lassus Saint-Geniès

Especies en movimiento: la Convención sobre el Comercio Internacional de Especies Amenazadas de Fauna y Flora Silvestres como espacio de “Encuentro” de discursos, ACTORES Y ESTRATEGIAS EN EL DERECHO AMBIENTAL TRASNACIONAL

María Valeria Berros e Dabel Leandro Franco

El carácter transnacional del Sistema comunitario de ECogestion « Eco-ManageMENT AND Audit SCHEME » (EMAS) DENTRo de LA UE y MÁs ALlÁ DE SUS Fronteras ......72 Adélie Pomade

O CONCEITO DE CONDUTA EMPRESARIAL RESPONSÁVEL À LUZ DOS ORDENAMENTOS JURÍDICOS BRASILEIRO, INTERNACIONAL E TRANSNACIONAL

Gabriel Webber Ziero

ARBITRAGEM NO DIREITO TRIBUTÁRIO INTERNACIONAL E NO DIREITO INTERNACIONAL DOS INVESTIMENTOS: UMA MANIFESTAÇÃO DO DIREITO TRANSNACIONAL

Vivian Daniele Rocha Gabriel 
O DIREITO TRIBUTÁRIO SOB UMA PERSPECTIVA TRANSNACIONAL

Franciele de Simas Estrela Borges

As Características do Direito Transnacional como Metodologia: Análise sob o enfoQue dos Aspectos Processuais da Arbitragem 126

Flávia Foz Mange

O DIREITO TRANSNACIONAL (“GLOBAL LAW") E A CRISE DE PARADIGMA DO ESTADO-CENTRISMO: É POSSÍVEL CONCEBER UMA ORDEM JURÍDICA TRANSNACIONAL? ...................................... 146

Luiza Nogueira Barbosa e Valesca Raizer Borges Moschen

TransPorte AÉREO E DIREITO TRANSNACIONAL: DA CONVERGÊNCIA À UNIFORMIDADE 160 Mickael R. Viglino

Outros Artigos. 175

O Fundo Monetário Internacional e a proteção dos direitos humanos: uma análise DO PROGRAMA DE CRESCIMENTO E REDUÇÃO DA POBREZA NO HAITI 177

Pablo Henrique Hubner de Lanna Costa e Carlos Alberto Simões de Tomaz

Um estranho no ninho? Padrões privados no Acordo de Barreiras Técnicas ao CoMÉRCIO DA OMC 192

Michelle Ratton Sanchez Badin e Marina Yoshimi Takitani

Os benefícios tributários do programa Inovar-Auto e os princípios da Nação Mais Favorecida e do Tratamento Nacional: uma análise dos argumentos dos Painéis atualmente em Curso contra o Brasil no Órgão de SoluÇão de Controvérsias da OMC . 211 Eric Moraes Castro e Silva

A ERA DA HUMANIDADE: REFLEXões PARA A HISTÓRIA DO DIREITO INTERNACIONAL 236 Henrique Weil Afonso

Precedentes vinculantes nos Estados Unidos da América e no direito brasileiro: Um ESTUDO COMPARADO 264

Patrícia Perrone Campos Mello 
IL DIRITTO AMBIENTALE SECONDO L'OTTICA DEL DIRITTO COSTITUZIONALE POSITIVO E LA RESPONSABILITÀ PER DANNI ALL'AMBIENTE NEL DIRITTO COMUNITARIO: LO STATO DELL'ARTE DEL DIRITTO AMBIENTALE COSTITUZIONALE E COMUNITARIO 287

Elcio Nacur Rezende

DA DESCONSIDERAÇÃo DA PERSONALIDADE JURÍDICA NAS RELAÇÕES CONSUMEIRISTAS BRASILEIRAS: ANÁLISE À LUZ DAS TEORIAS CLÁSSICAS

Daniel Amin Ferraz e Marcus Vinicius Silveira de Sá

ANALYSIS OF ADVANTAGES AND DISADVANTAGES OF FORUMS PRESCRIBED UNDER THE UNCLOS AND STATE PRACTICE: THE WAY AHEAD FOR INDIA ......................................................319

Vinai Kumar Singh

Do governo POR LEIS À governanÇA POR NúMERos: breve anÁlise do Trade in SERVICE AgreEMENT (TISA) ...............................................................................338 Jânia Maria Lopes Saldanha, Rafaela da Cruz Mello e Têmis Limberger

As DIRETIVAS EUROPEIAS COMO NORMA REGULADORA DO DIREITO ADMINISTRATIVO GLOBAL ..356 Alice Rocha da Silva e Ruth Maria Pereira dos Santos

O desenVolvimento da POlítica AGRícola COMUM dA UNião EUROPEIA 375 Tatiana de A. F. R. Cardoso Squeff

A IMUNidAde DE JURISDiÇÃo DAS ORGANIZAÇÕES INTERNACIONAIS FACE AO DIREITO DE ACESSO À JUSTIÇA 391

Fernanda Araújo Kallás e Caetano

O DIREITO INTERNACIONAL ENTRE O DEVER ÉTICO E A AÇÃo POLÍ́TICA: OS FUNDAMENTOS DE UM DEVER DE COOPERAÇÃO INTERNACIONAL NA FILOSOFIA POLÍTICA DE IMMANUEL KANT .405 Ademar Junior Pozzatti

EXTENSÃo E FRAGMENTAÇÃo NO CONTEXTO DA JURISDIÇÃO PENAL INTERNACIONAL .423 Marcus Vinícius Xavier de Oliveira

A DEFINIÇÃo JURÍdiCA DA “COMUNIDAdE" 444 Nitish Monebhurrun, Michelle Lucas Cardoso Balbino, Fernanda Castelo Branco Araujo, Othon Pantoja, Maíra Bogo Bruno e Cândida Dettenborn Nóbrega 
Comparative Study on Chinese Local Legislation of Science and Technology ProGRESS

LI Xiaoming e LI Yihan

O CONTROLE PENAL DO TRÁFICO DE PESSOAS: CONSTRUÇÃO JURÍDICA, INTERAÇÕES ORGANIZACIONAIS E COOPERAÇÃO INTERNACIONAL

Bruno Amaral Machado e Priscilla Brito Silva Vieira

Desativismo judicial: a extradição Battisti no Supremo Tribunal Federal .505 Francisco Rezek e Israel Paulino

A decisão norte-americana do Caso Myriad: novos paradigmas para a Proteção patenTÁRIA DO CÓDIGO GENÉTICO HUMANO E BIOTECNOLOGIA 514 José Carlos Vaz e Dias e Clarisse De La Cerda 


\title{
O conceito de conduta empresarial responsável à luz dos ordenamentos jurídicos brasileiro, internacional e transnacional*
}

\author{
The concept of responsible business conduct \\ in the light of the brazilian, international and \\ transnational legal systems
}

Gabriel Webber Ziero**

\section{Resumo}

O objetivo deste artigo é analisar, com base no conceito de conduta empresarial responsável, as interações do direito brasileiro com os direitos internacional e transnacional, em particular, como essas três ordens jurídicas interagem, de forma conjunta, para que juntas possam determinar o que se espera da conduta empresarial. Para tal fim, realiza-se uma análise teórico-conceitual da literatura jurídica, em especial a estrangeira de matriz anglófona, bem como de um estudo de caso. As duas primeiras seções dedicam-se a explorar o conceito de direito transnacional, analisando em particular as interações normativas entre o direito transnacional e os direitos internacional e nacional. A fim de aprofundar tal problemática, bem como contribuir para com os debates acerca do direito transnacional a partir de uma outra perspectiva, este artigo concentra-se no conceito de conduta empresarial responsável, oriundo da esfera transnacional, o qual é apresentado de modo breve na terceira parte. Na sequência, as interações normativas entre o direito brasileiro via o princípio da função social da empresa com os direitos internacional e transnacional são analisadas à luz do conceito de conduta empresarial responsável. Visando exemplificar como tais interações ocorrem na prática, sejam elas convergentes ou divergentes, é realizado um estudo de caso no contexto da produção de soja. Por fim, conclui-se que a complexidade inerente de tais interações deve ser vista por meio de seu potencial transformador contribuindo para a superação de uma interpretação hermética do direito brasileiro fazendo com que parâmetros oriundos das ordens internacional e transnacional sejam também levados em consideração.

Palavras-chave: Direito transnacional. Conduta empresarial responsável. Função social da empresa. Direito brasileiro. Interações normativas.

* Recebido em 26/08/2016 Aprovado em 10/09/2016

** Doutorando em Direito na Universidade de Roma Ter (Discipline giuridiche storicofilosofiche, internazionali, sovranazionali e comparate). Mestre em Direito pelo Programa de Estudos Avançados em Direito Internacional Público da Universidade de Leiden. E-mail: gabrielziero@gmail.com.

\section{Abstract}

This paper seeks to analyse the interactions of Brazilian law with international and transnational law in the light of the concept of responsible business conduct. In particular, this paper aims at exploring how these three 
legal orders interact in order to jointly determine what is expected from corporate conduct. In order to do so, this research engages in a conceptual and theoretical analysis of legal literature, in particular in English, as well as a case study. The first two sections are dedicated to address the concept of transnational law as well as the normative interactions between transnational, international, and national law. In order to further elaborate on this issue and to contribute to the debates around transnational law from a different perspective, this paper focuses on the concept of responsible business conduct that has emerged from the transnational space and which is briefly introduced in the third part. In the sequence, the normative interactions with respect to the concept of responsible business conduct between Brazilian law, via the principle of company's social function, with the international and transnational law are analysed. After, in order to illustrate how these interactions, may they be convergent or divergent, occur in practice a case study in the context of soybean production is presented. Finally, it is concluded that the inherent complexities of these normative interactions should be seen as an opportunity for transformation, which can contribute to overcome a hermetic interpretation of Brazilian law by including also concepts emerging from international and transnational orders.

Keywords: Transnational law. Responsible business conduct. Company's social function. Brazilian law. Normative interactions.

\section{INTRODUÇÃO}

Atividades empresariais, bem como os efeitos dessas não conhecem fronteiras e podem ser observados nas mais remotas partes do globo terrestre. Contudo, os modelos regulatórios, bem como as técnicas de interpretação jurídica, comumente adotadas por operadores jurídicos, gravitam entorno de conceitos territoriais. Por exemplo, pode-se mencionar as inúmeras discussões acerca do direito aplicável e do juízo competente para julgar questões envolvendo empresas transnacionais. ${ }^{1}$

1 Por exemplo, tais questões são abordadas por Fornasier e Ferreira em artigo publicado anteriormente nessa Revista: FORNASIER, Mateus de Oliveira; FERREIRA, Luciano Vaz. A regulação das empresas transnacionais entre as ordens jurídicas estatais e não estatais. Revista de Direito Internacional, Brasília, v. 12, n. 1, p. 395-414, jun. 2015.
Para surpresa de muitos, não são apenas empresas que operam ou fazem negócios em diversos países que devem estar atentas a tais questões. Cada vez mais, organizações não governamentais, órgãos setoriais ou instituições reguladoras de setores produtivos esperam que empresas adotem uma conduta empresarial responsável (CER), o que compreende observar não apenas regulações nacionais, mas também normas oriundas dos ordenamentos jurídicos internacional e transnacional.

Contudo, uma breve análise da prática forense e da literatura jurídica brasileira, em especial aquela relacionada ao princípio constitucional da função social da empresa, revela uma interpretação e aplicação hermética do conceito de função social, ou seja, sem levar em consideração normas provenientes das ordens internacional e transnacional. Ademais, no contexto brasileiro, ao passo que discussões acerca das relações entre direito nacional e direito internacional venham ganhando espaço de forma gradativa, os debates relacionados ao direito transnacional são, ainda, incipientes seja no campo acadêmico ou prático. ${ }^{2}$

Logo, o presente artigo visa contribuir para com os debates sobre como o direito brasileiro interage com as ordens jurídicas internacional e transnacional. Destarte, com base no conceito de conduta empresarial responsável, oriundo da esfera transnacional, esse artigo explora as interações do direito brasileiro com os direitos internacional e transnacional, em particular, como essas três ordens jurídicas interagem de forma conjunta para que juntas possam determinar o que se espera da conduta empresarial. Ou seja, a contribuição guia-se pela seguinte pergunta: como os ordenamentos jurídicos brasileiro, internacional e transnacional interagem à luz do conceito de conduta empresarial responsável para determinarem os parâmetros da conduta empresarial? A fim de responder tal questionamento, realiza-se uma análise teórico-conceitual da literatura estrangeira, em especial a de matriz anglófona, ${ }^{3}$ bem como um estudo

2 Veja, por exemplo, o artigo de Faria, publicado anteriormente nessa Revista, que aborda as interações entre os ordenamentos jurídicos brasileiro e transnacional no âmbito do direito desportivo. FARIA, Tiago Silveira de. A influência do direito desportivo transnacional no ordenamento jurídico brasileiro: da reprodução de normas à aplicação direta pela jurisdição estatal. Revista de Direito Internacional, Brasília, v. 12, n. 2, p. 323-340, dez. 2015.

3 Nesse sentido, deve-se ressaltar que ainda que soluções propostas pelas doutrinas francófona e de língua portuguesa serem mencionadas, bem como algumas de suas posições adotadas ao longo desse artigo, em particular a solução de conflitos normativos via o chamado dialogue des sources, o presente artigo não explora tais 
de caso visando exemplificar as interações entre as três ordens jurídicas.

Dessa forma, o artigo estrutura-se em cinco partes. As duas primeiras dedicam-se a explorar, bem como a contribuir para com os debates acerca do conceito de direito transnacional. Sendo assim, a primeira parte apresenta as discussões doutrinarias acerca do que é direito transnacional, bem como propõe um conceito de direito transnacional visando obter uma coerência conceitual ao longo desse artigo. Na sequência, partindo desse conceito base, observam-se algumas dinâmicas relativas ao direito transnacional, por exemplo, a participação de diversos atores sociais.

Após explorar a ideia de direito transnacional, a terceira parte deste artigo apresenta o conceito de conduta empresarial responsável, o qual origina-se no campo transnacional. Na sequência, a quarta seção a partir do conceito de CER observa como o direito brasileiro, como base no princípio da função social da empresa, interage com o direito internacional, em especial com os pilares da obrigação estatal de proteger e a responsabilidade de privados de respeitar direitos humanos, e com o direito transnacional para que juntos possam determinar o que se espera da conduta empresarial. Por fim, demonstra-se como a interação entre os três ordenamentos jurídicos ocorre num contexto prático, nesse caso o da produção de soja.

\section{Direito transnacional: Um CONCEito EM CONSTRUÇÃO}

O pensamento jurídico moderno encontra-se centrado no direito de origem estatal, ou seja, o Estado possui o monopólio do ius dicere seja no âmbito das relações internas (direito nacional), seja nas relações envolvendo outros Estados (direito internacional). As limitações inerentes da díade direito nacional $3 / 4$ direito internacional tornaram-se cada vez mais evidentes, ao passo que a ideia de uma possível terceira ordem jurídica abrangendo questões que escapem aos limites estabelecidos pelos âmbitos nacional e internacional pode ser encontrada na literatura jurídica desde o século XVIII. Por exemplo, é possível observar tal hipótese em Kant que,

debates em profundidade, uma vez que esses já são objeto de vasta produção e pesquisa acadêmica no Brasil (por exemplo veja nota de rodapé 28). em seu livro À Paz Perpétua, propunha a adoção de um direito cosmopolita a fim de superar os limites postos pela díade direito nacional $3 / 4$ direito internacional no que tange a proteção de estrangeiros, ${ }^{4}$ bem como nos escritos do próprio Bentham, que cunhou a expressão direito internacional tal qual a compreendemos hoje, ou seja, como o direito entre Estados Soberanos. ${ }^{5}$

Contudo, no início da segunda metade do século $\mathrm{XX}$, problemas jurídicos localizados para além dos domínios do direito interno, mas que ao mesmo tempo não atendiam os requisitos necessários para se enquadrarem na esfera de aplicação do direito internacional, ou seja, não eram questões entre Estados, passaram a se tornar cada vez mais frequentes. Como exemplos característicos desse período, podem-se mencionar as disputas judiciais envolvendo empresas multinacionais e Estados seja na reconstrução da Europa no pós-guerra, seja na exploração de petróleo no Oriente Médio. Diante desse cenário, Phillip Jessup, que depois viria a se tornar juiz da Corte Internacional de Justiça, publicou a obra seminal intitulada Transnational Law. ${ }^{6}$

Nessa obra, Jessup problematiza não apenas as limitações do direito internacional ao lidar com atores não estatais, tais como empresas multinacionais, mas também adota o termo direito transnacional diante de sua insatisfação com a expressão direito internacional. Em contraposição a ideia sectária presente na definição clássica de direito internacional, ou seja, a de direito aplicável apenas nas relações entre Estados Soberanos, Jessup introduz o direito transnacional como um conceito capaz de abarcar as expressões normativas aplicáveis aos eventos que transcendem as fronteiras do Estado-Nação. ${ }^{7}$ Assim, desde os anos 1950, o proto conceito de direito transnacional ${ }^{8}$ apresentado por Jessup vem sendo objeto de estudos e elaborações doutrinárias.

Para Koh, por exemplo, o direito transnacional deve ser visto como um meio de se compreender como di-

4 KANT, Immanuel. À pazperpetua. São Paulo: L\&PM, 2010.

5 BENTHAM, Jeremy. The principles of international law. Available in: <http://www.laits.utexas.edu/poltheory/bentham/pil/index. html>. Access: 07 jul. 2016. Veja também: JANIS, Mark W. Jeremy Bentham and the fashioning of international law. American Journal of International Law, v. 78, n. 2, p. 405-418, abr. 1984.

6 JESSUP, Philip. Transnational law. New Haven: Yale University Press, 1956.

7 JESSUP, Philip. Transnational law. New Haven: Yale University Press, 1956. p. 1-2.

8 SCOTT, Craig. Transnational law as a proto-concept: three conceptions. German Law Journal, v. 10, n. 7, p. 859-876, jul. 2009. 
versos atores internalizam em suas práticas normas de direito internacional. ${ }^{9}$ Além disso, para o autor, o direito transnacional representa o futuro da ordem jurídica internacional, uma vez que esse representaria uma ruptura no modelo Westfaliano de direito internacional, pois permitiria a inclusão de diversos atores para além dos Estados. ${ }^{10}$ Contudo, tal acepção é criticada por internacionalistas que seguem uma interpretação positivista do direito internacional, uma vez que entendem que o produto das interações entre atores estatais e não estatais não pode ser definido como direito internacional, uma vez que tais regulações não se enquadram no paradigma fundante da disciplina, ou seja, ser o produto normativo das relações entre Estados. ${ }^{11}$

Já outros autores, por exemplo Noortmann, compreendem o direito transnacional como uma ordem jurídica autônoma das ordens nacional e internacional, mas que, ao mesmo tempo, parcialmente, justapõe-se a tais ordens jurídicas. ${ }^{12}$ Por outro lado, Halliday e Shaffer descrevem o direito transnacional como um processo dialógico-normativo resultante das interações entre diversos atores sociais, tais como Estados, associações locais, empresas multinacionais e organizações não-governamentais de caráter internacional. O resultado dessas interações, via de regra, são dispositivos que podem ser reconhecidos e observados por diversos atores sociais como normas, mesmo não sendo a priori vinculantes. ${ }^{13} \mathrm{~A}$ título exemplificativo, podem-se mencionar documentos redigidos dentro de uma lógica regulatória, tais como códigos de governança a exemplo dos Princípios de Governança Corporativa G20/OCDE ${ }^{14}$ que

$9 \mathrm{KOH}$, Harold. Transnational legal process. Nebraska Law Review, v. 75, n. 1, p. 181-207, jan. 1996.

$10 \mathrm{KOH}$, Harold. Remarks: twenty-first-century international lawmaking. The Georgetown Law Journal, v. 101, n. 3, p. 725-747, may 2013. 11 D'ASPREMONT, Jean. From a pluralisation of international norm-making process to a pluralization of the concept of international law. In: PAUWELYN, Joost; WESSEL, Ramses; WOUTERS, Jan. Informal international lawmaking. Oxford: Oxford University Press, 2012. p. 185-199.

12 NOORTMANN, Math. Transnational law: Philip Jessup's Legacy and Beyond. In: NOORTMANN, Math; REINISCH, August; RYNGAERT, Cedric. Non-state actors in international law. Oxford: Hart Publishing, 2015. p. 57-74.

13 HALLIDAY, Terence; SHAFFER, Gregory. Transnational legal orders. Cambridge: Cambridge University Press, 2015. p. 4-15.

14 ORGANISATION FOR ECONOMIC CO-OPERATION AND DEVELOPMENT. Principles for corporate governance. 2015. Available in: <http://dx.doi.org/10.1787/9789264236882-en>. Access: 07 jul. 2016. Mesmo tendo sido adotado pelos Estadosmembro da Organização para a Cooperação e Desenvolvimento Econômico (OCDE), bem como pelos líderes do Grupo dos 20, os mesmo sua observância não sendo vinculante é exigida por diferentes atores sociais, como, por exemplo, agências reguladoras tais quais o Financial Stability Board. ${ }^{15}$

Como observado, o proto conceito de direito transnacional possui várias acepções. Além disso, diferentemente de outras correntes doutrinárias que visam estudar como o direito responde os desafios de um mundo globalizado, tais como Direito Administrativo Global (Global Administrative Law $)^{16}$ e Informal International Lawmaking (IN-LAW) ${ }^{17}$ que se baseiam numa noção estado-cêntrica de direito, o direito transnacional apresenta uma estrutura policêntrica, em que o Estado não detém nenhum tipo de monopólio sobre os processos relacionados com tal direito, uma vez que esse o compartilha com outros atores sociais. ${ }^{18}$ Logo, baseando-se nas visões acima mencionadas e visando maior coerência conceitual ao longo deste artigo, propõe-se uma leitura do conceito de direito transnacional como a ordem jurídica que se dedica a questões que ao mesmo tempo ultrapassam e confundem os limites que caracterizam o direito interno e o direito internacional estruturando-se sob critérios de inclusão e diversidade que se evidenciam tanto no que tange a participação de atores, como no que se refere aos temas abraçados por tal ordem jurídica.

Princípios de Governança Corporativa devem ser compreendidos tanto como norma de direito internacional (soft law), como de direito transnacional, tendo em vista que o seu processo de elaboração incluiu diversos atores sociais, tais como, empresas, investidores, governos e organizações da sociedade civil, bem como sua aplicação confunde os limites tradicionais atribuídos ao direito internacional.

15 FINANCIAL STABILITY BOARD. Key standards for sound financial systems. Available in: <http://www.fsb.org/what-we-do/ about-the-compendium-of-standards/key_standards/>. Access: 07 jul. 2016.

16 KINGSBURY, Benedict; KIRSCH, Nico; STEWART, Richard. The emergence of global administrative law. Law and Contemporary Problems, v. 68, n. 15, p. 15-61, 2005. Em língua portuguesa, refere-se a: POSTIGA, Andréa Rocha. A emergência do direito administrativo global como ferramenta de regulação transnacional do investimento estrangeiro direto. Revista de Direito Internacional, Brasília, v. 10, n.1, p. 171-193, 2013.

17 PAUWELYN, Joost; WESSEL, Ramses; WOUTERS, Jan. Informal international lawmaking. Oxford: Oxford University Press, 2012.

18 ZUMBANSEN, Peer. Neither 'public' nor 'private', 'national' nor 'international': Transnational corporate governance from a legal pluralistic perspective. Journal of Law and Society. v. 38 n. 1, p. 50-75, mar. 2011. Nesse sentido, pode-se dizer que o Estado vem assumir um papel articular junto a diversos atores sociais, como debatido por Santos em: SANTOS, Boaventura de Sousa. Para uma revolução democrática da Justiça. Coimbra: Almedina, 2014. p. 48, 96-97. 


\section{Direito transnacional em movimento}

Partindo-se do conceito base adotado acima, podem ser mencionados dois exemplos de normas de direito transnacional que, ao mesmo tempo, ultrapassam e confundem os limites que caracterizam o direito interno e o direito internacional, quais sejam o Código de Governança Corporativa alemão ${ }^{19}$ e o Processo Kimberley de Certificação de Diamantes ${ }^{20}$. Tais regulações transnacionais, mesmo tendo sido criadas por delegação proveniente do direito interno ou internacional, não são reconhecidas como pertencentes a tais ordens jurídicas, uma vez que seus processos de criação, implementação, cumprimento e coerção extrapolam os limites tradicionalmente estabelecidos tanto pelo direito interno, como pelo direito internacional. Logo, essa parte busca analisar as dinâmicas em torno do direito transnacional, em especial as que se referem aos atores envolvidos no processo de criação de normas e a resolução de eventuais conflitos normativos entre direito transnacional e direito interno ou internacional.

No que se refere aos sujeitos no campo do direito transnacional, a sua participação não é limitada a um critério exclusivo, estático e geral como nos ordenamentos interno e internacional, mas tal categoria deve ser compreendida como aberta, fluída e específica, uma vez que visa abranger todos os atores independentemente de suas características que estão envolvidos em determinada situação. Por exemplo, uma organização não governamental ou empresa, à luz dos critérios utilizados pelo direito internacional, não podem ser consideradas como sujeitos de direito internacional, mas podem vir a serem consideradas sujeitos de direito transnacional enquanto participantes de um determinado processo normativo. Tal particularidade do direito transnacional, em relação ao que se refere a sua pluralidade de atores, deve-se ao fato de que este é centrado, como apontado por Jessup ${ }^{21}$ nas questões e nos problemas que ultrapas-

19 ALEMANHA. Deutscher corporate governance kodex. 2015. Available in: <http://www.dcgk.de//files/dcgk/usercontent/en/download/code/2015-05-05_Corporate_Governance_Code_EN.pdf $>$ Access: 07 jul. 2016. Veja também: ZUMBANSEN, Peer. Neither 'public' nor 'private', 'national' nor 'international': Transnational corporate governance from a legal pluralistic perspective. Journal of Law and Society. v. 38 n. 1, p. 50-75, mar. 2011.

20 KIMBERLEY PROCESS CERTIFICATION SCHEME. Kimberley process certification scheme core document. Available in: $<$ https://www.kimberleyprocess.com/en/kpcs-core-document $>$. Access: 07 jul. 2016.

21 JESSUP, Philip. Transnational law. New Haven: Yale University sam as fronteiras nacionais e os limites metodológicos dos direitos nacional e internacional.

Assim, de acordo com Zumbansen, a própria noção de Direito no campo transnacional deve ser repensada para além de critérios eminentemente normativos e sancionatórios, para que possa incluir o seu caráter de ferramenta mediadora e facilitadora na relação entre diversos atores ao tratarem questões transfronteiriças comuns. ${ }^{22}$ Logo, o direito transnacional deve ser compreendido como o produto normativo dos processos de interação entre diversos atores sociais que orientam a prática desses em situações que ultrapassam e confundem os limites que caracterizam o direito interno e o direito internacional.

Tais características do direito transnacional podem ser evidenciadas no estudo de uma de suas fontes, as regulações privadas transnacionais (RPT) que são um conjunto de processos e regulamentos resultante da interação entre diversos atores, em sua maioria agentes não estatais, como por exemplo, empresas e organizações não governamentais (ONGs), ${ }^{23}$ que visam regulamentar setores industriais e/ou cadeias produtivas e não apenas as atividades de determinada empresa ou grupo empresarial, que são objeto dos chamados códigos de conduta empresarial. ${ }^{24}$ Além disso, RPT podem ser criadas de forma autônoma, ou seja, a motu proprio pelos atores envolvidos ${ }^{25}$ visando regular determinada atividade ou por

Press, 1956.

22 ZUMBANSEN, Peer. Neither 'public' nor 'private', 'national' nor 'international': Transnational corporate governance from a legal pluralistic perspective. Journal of Law and Society. v. 38 n. 1, p. 50-75, mar. 2011.

23 CAFAGGI, Fabrizio. New foundations of transnational private regulations. Journal of Law and Society. v. 38 n. 1, p. 20-49, mar. 2011. 24 Fornasier e Ferreira em artigo publicado anteriormente nessa Revista realizam uma discussão acerca dos códigos de conduta empresarial, como verdadeiras ordens jurídicas. FORNASIER, Mateus de Oliveira; FERREIRA, Luciano Vaz. A regulação das empresas transnacionais entre as ordens jurídicas estatais e não estatais. Revista de Direito Internacional, Brasíla, v. 12, n. 1, p. 395-414, jun. 2015. Vale ainda ressaltar o artigo de Morais et. al. que analisa como códigos de conduta empresarial na área de responsabilidade socioambiental interagem com normas do direito brasileiro: MORAIS, Dulce Teresinha Barros Mendes de et. al. O papel do direito no contexto do desenvolvimento sustentável: uma avaliação qualitativa de programas corporativos de responsabilidade socioambiental. Revista de Direito Internacional, Brasília, v. 9, n. 3, p. 141-158.

25 É importante ressaltar que, regulações privadas transnacionais não se confundem com a chamada lex mercatoria, seja essa compreendida em sua concepção tradicional ou mais recente (nova lex mercatoria), uma vez que as dinâmicas em tono das RPT envolvem a participação de uma pluralidade de atores sociais, o que não é o caso das interações em torno da lex mercatoria. Para uma discussão 
meio de delegação oriunda dos ordenamentos jurídicos nacional e internacional. Como exemplo de RPT, pode-se mencionar o Código de Conduta Internacional para Provedores de Serviços de Segurança Privada, criado de forma conjunta por ONGs, Estados, empresas de segurança privada e acadêmicos, para lidar com abusos de direitos humanos cometidos por empresas de segurança privada. ${ }^{26}$ Além disso, RPT mesmo não sendo vinculantes podem vir a ser exigidas ou reconhecidas como critérios mínimos de conduta por diversos atores sociais (ex. instituições financeiras) ${ }^{27}$ como é o caso das regulações como as adotadas pelo Forest Stewardship Council (FSC) no que tange ao manejo de áreas de floresta.

Os ordenamentos interno, internacional e transnacional, ao interagirem entre si diante de situações concretas, por exemplo, na regulamentação da atividade empresarial, acabam por complementar-se ou por entrar em conflito devido a dispositivos divergentes. Assim, ainda que existam critérios para a resolução de conflitos normativos entre normas de direito interno e direito internacional, este não se pode dizer para conflitos envolvendo normas oriundas desses ordenamentos jurídicos com normas de direito transnacional.

Tendo em vista as diferenças intrínsecas entre normas de direito transnacional para com normas de direito interno e internacional, a solução de tais conflitos normativos via a utilização dos tradicionais critérios de hierarquia, temporalidade e especificidade não se mostra a mais adequada, uma vez que tais técnicas acabam por não abarcar todas as especificidades e complexidades presentes no caso concreto onde tal interação ocorre. Dessa forma, diante de tal complexidade, torna-se

acerca do conceito de lex mercatoria, indica-se o artigo de Tomazzette publicado anteriormente nessa Revista. TOMAZETTE, Marlon. Internacionalização do direito além do Estado: a nova lex mercatoria e sua aplicação. Revista de Direito Internacional, Brasília, v. 9, n. 4, 2012, p. 93-121.

26 INTERNATIONAL CODE OF CONDUCT ASSOCIATION. The international code of conduct for private security service providers. Available in: < http://www.icoca.ch/en/the_icoc $>$. Access: 07 jul. 2016.

27 ENVIRONMENTAL \& Social Risk Policy Framework. 2015. Available in: < https://www.ubs.com/ global/en/about_ubs/corporate_responsibility/howwe-do-business/protecting-people-and-planet/environmentaland-social-risks/_jcr_content/par/linklist_0/link_0.2049074265. file/bGluay9wYXRoPS9jb250ZW50L2RhbS9zdGF0aWMvZ2xvYmFsL2Fib3V0X3Vicy9jb3Jwb3JhdGVfcmVzcG9uc2liaWxpdHkvdWJzLWVzci1 mcmFtZXdvcmstdXBkYXRILTIwMTYtZW4ucGRm/ubs-esr-framework-update-2016-en.pdf> Access: 07 jul. 2016. necessário, como defende Jayme, que tais conflitos normativos sejam resolvidos por meio de um diálogo entre as normas que incidem sobre determinada situação a fim de que se encontre uma solução que atenda os valores que informam tais ordens jurídicas. ${ }^{28}$

Logo, a fim de ilustrar como esse diálogo normativo entre os ordenamentos interno, internacional e transnacional ocorre, as próximas seções deste artigo se dedicam a explorar as dinâmicas em torno do conceito de conduta empresarial responsável que vem sendo cada vez mais utilizado por diferentes atores sociais, tais como empresas, governos e organizações da sociedade civil, tendo em vista as limitações inerentes as ordens jurídicas brasileira e internacional que gravitam em torno de conceitos territoriais. Dessa forma a próxima parte deste artigo explora, de forma breve, o conceito de conduta empresarial responsável, para que a seguir se analise à luz da ideia de CER as interações do direito brasileiro com as ordens internacional e transnacional.

\section{Breve nota aCERCA DO CONCEITO de CONDUTA EMPRESARIAL RESPONSÁVEL}

O conceito de conduta empresarial responsável (CER) demanda que empresas, ao longo de suas operações, observem não apenas regulações nacionais, mas também normas oriundas dos ordenamentos internacional e transnacional. A ideia de CER vem sendo difundida com base na atuação da Organização para a Cooperação e Desenvolvimento Econômico (OCDE), em especial no que diz respeito as Diretrizes OCDE para Empresas Multinacionais (Diretrizes da OCDE) lança-

28 JAYME, Erik. Identité culturelle et intégration: le droit international privé postmoderne. Recueil des Cours de l'Académie de Droit International de La Haye, v. 221, n. 9, 1995. No contexto brasileiro deve-se ressaltar no que tange a teoria do diálogo das fontes, o trabalho realizado pela internacionalista Claudia Lima Marques, por exemplo na obra: MARQUES, Claudia Lima (Coord.). Diálogo das fontes: do conflito à coordenação de normas do direito brasileiro. São Paulo: Revista dos Tribunais, 2014. MARQUES, Claudia Lima. Diálogo entre o código de defesa do consumidor e o novo código civil: do 'diálogo das fontes' no combate às cláusulas abusivas. Revista de Direito do Consumidor, São Paulo, v. 45, p. 71-99, 2003. Ainda, vale ressaltar, as observações realizadas por Santana e Vial acerca das teorias de Jayme e Marques sobre o diálogo das fontes no que tange as interações entre o direito brasileiro e o direito internacional privado: SANTANA, Héctor Valverde; VIAL, Sophia Martini. Proteção internacional do consumidor e cooperação interjurisdicional. Revista de Direito Internacional, Brasília, v. 13, n. 1, p. 397-418, 2016. 
das na década de $1970 .{ }^{29}$ Contudo, a noção de CER não se encontrava presente no documento ainda que fosse possível depreendê-la de uma leitura das primeiras versões das Diretrizes da OCDE com um enfoque baseado na proteção aos direitos humanos e ao meio ambiente. A inclusão do termo conduta empresarial responsável no texto das Diretrizes da OCDE só veio a ocorrer no preâmbulo da versão do ano 2000. No entanto, foi na versão de 2011 que o conceito de CER foi incorporado aos dispositivos das Diretrizes da OCDE, bem como passou a desempenhar uma função central na aplicação e implementação dessas, refletindo os desenvolvimentos causados pela adoção dos Princípios Orientadores para Empresas e Direitos Humanos da Organização das Nações Unidas (Princípios para Empresas e Direitos Humanos). ${ }^{30}$

É importante ressaltar que, apesar de o conceito de conduta empresarial responsável ter sido incorporado pelas Diretrizes da OCDE, ou seja, um documento de direito internacional (soft law), este encontra suas origens, bem como sua propagação no campo transnacional. Ou seja, a ideia de CER é produto de uma construção coletiva entre diversos atores sociais, tais como governos, organizações internacionais, empresas, sindicatos e sociedade civil, e, mesmo tendo sido incorporada pelas Diretrizes da OCDE, o conceito estende-se para além dos limites que caracterizam o direito internacional. Ademais, ainda que o conceito de conduta empresarial responsável possua o mesmo ponto de partida da já conhecida e amplamente utilizada ideia de responsabilidade social da empresa (RSE), qual seja o de fazer com que empresas passem a levar em consideração durante suas operações assuntos relacionados ao interesse coletivo, por exemplo proteção do meio ambiente e respeito a direitos humanos, a forma com que CER e RSE se manifestam é divergente.

A noção de responsabilidade social da empresa esteve, historicamente, associada ao filantropismo e a uma análise estritamente economicista do papel da ativida-

29 ORGANIZAÇÃO PARA A COOPERAÇÃO E DESENVOLVIMENTO ECONÔMICO. Diretrizes da Organização para a Cooperação e Desenvolvimento Econômico para empresas multinacionais. 2011. Disponível em: < http://www.pcn.fazenda.gov.br/ assuntos/ocde/arquivos/2011-diretrizes-da-ocde-para-empresasmultinacionais-pt-br.pdf>. Acesso em: 07 jul. 2016.

30 UNITED NATIONS. Protect, respect and remedy: a framework for business and human rights: report of the on the issue of human rights and transnational corporations and other enterprises, John Ruggie. 2008. UN Doc: A/HRC/8/5. de empresarial em que ações relativas a RSE não estão integradas aos propósitos e fins da empresa, ou seja, não se integram aos seus procedimentos internos, uma vez que tais ações são vistas como um "extra". ${ }^{31}$ Sendo assim, muitas vezes, por mais que empresas estivessem a par do potencial de geração de risco socioambiental de suas atividades, estas não encontravam respostas em suas políticas de RSE sobre como poderiam operacionalizar estratégias de prevenção de danos e mitigação de abusos cometidos.

O conceito de conduta empresarial responsável, por sua vez, busca potencializar o poder transformador e de impacto positivo de empresas juntamente às sociedades em que atuam (tal como a ideia de RSE), aliando suas práticas a diretrizes e critérios, via de regra, setoriais que auxiliem empresas a operacionalizar ações na área de CER visando adotar estratégias de prevenção de danos e mitigação de abusos cometidos. Contudo, ações vinculadas a CER não podem ser criadas de modo isolado, tais quais as de RSE, pois estas pressupõem para sua criação um processo participativo entre diversos atores atuantes em determinado setor produtivo, bem como aqueles que são afetados pelas atividades desenvolvidas por tal setor. ${ }^{32}$ Ademais, para além dos tradicionais temas voltados à proteção do meio ambiente e respeito aos direitos humanos, abordados por ações na área de RSE, o enfoque de CER também volta-se para áreas como relações de trabalho e responsabilidade financeira, em especial, o combate à corrupção e à evasão fiscal..$^{33}$ Além disso, uma vez que CER caracteriza-se por estabelecer critérios mínimos esperados de determinado setor, empresas são demandadas a adequar seus procedimentos internos à luz de tais diretrizes por diversos atores sociais, tais como agências reguladoras e instituições financeiras.

Sendo assim, observa-se que o conceito de conduta empresarial responsável postula que empresas atuem

31 NIEUWENKAMP, Roel. 2016: CSR is dead! What's next? OECD insights: debate the issues. 2016. Available in: <http://oecdinsights.org/2016/01/22/2016-csr-is-dead-whats-next/>. Access: 07 jul. 2016.

32 NIEUWENKAMP, Roel. Legislation on responsible business conduct must reinforce the wheel, not reinvent it. In: LOVE, Patrick. Debate the issues: investment. Paris: OECD Publishing, 2016. p. 29-33. 33 ORGANIZAÇÃO PARA A COOPERAÇÃO E DESENVOLVIMENTO ECONÔMICO. Diretrizes da Organização para a Cooperação e Desenvolvimento Econômico para empresas multinacionais. 2011. Disponível em: < http://www.pen.fazenda.gov.br/ assuntos/ocde/arquivos/2011-diretrizes-da-ocde-para-empresasmultinacionais-pt-br.pdf>. Acesso em: 07 jul. 2016. 
de maneira consistente com as leis em vigor em determinado ordenamento jurídico interno, bem como com normas reconhecidas internacionalmente ${ }^{34}$ sejam estas oriundas do direito internacional (independentemente se o Estado onde essas operam tenham ou não ratificado tais normas) ou do direito transnacional. Logo, é possível afirmar que o conceito de CER não apenas pressupõe, mas também demanda a realização de um contínuo diálogo visando uma efetiva integração das três ordens jurídicas. Dessa forma, a próxima parte deste artigo analisa, por meio do conceito de CER, como o direito brasileiro, com base no princípio da função social da empresa, interage com o direito internacional, em especial com os pilares da obrigação estatal de proteger e a responsabilidade de privados de respeitar direitos humanos e com o direito transnacional para que juntos possam determinar o que se espera da conduta empresarial.

\section{INTERAÇÕES DO DIREITO BRASILEIRO COM AS ORDENS INTERNACIONAL E TRANSNACIONAL À LUZ DO CONCEITO DE CONDUTA EMPRESARIAL RESPONSÁVEL}

O conceito de conduta empresarial responsável encontra, no ordenamento jurídico brasileiro, ressonância juntamente ao princípio da função social presente no artigo 170, III da Constituição Federal de 1988 (CF/88), que orienta o regramento das relações entre empresas e sociedade. De acordo com Perez, tal princípio possui duas vertentes de aplicação. ${ }^{35} \mathrm{~A}$ primeira dedica-se ao incentivo e à preservação da atividade empresarial, uma vez que uma empresa, via de regra, gera, nos locais onde opera, empregos diretos e indiretos, paga tributos, bem como contribui para o desenvolvimento de determinada localidade. Tal vertente é a mais utilizada pela jurisprudência dos tribunais superiores brasileiros, principalmente em processos falimentares em que se visa à

34 ORGANIZAÇÃO PARA A COOPERAÇÃO E DESENVOLVIMENTO ECONÔMICO. Diretrizes da Organização para a Cooperação e Desenvolvimento Econômico para empresas multinacionais. 2011. Disponível em: < http://www.pcn.fazenda.gov.br/ assuntos/ocde/arquivos/2011-diretrizes-da-ocde-para-empresasmultinacionais-pt-br.pdf>. Acesso em: 07 jul. 2016.

35 PEREZ, Viviane. Função social da empresa: uma proposta de sistematização do conceito. In: ALVES, Alexandre Ferreira de Assumpção; GAMA, Guilherme Calmon Nogueira da (Coord.). Temas de direito civil-empresarial. Rio de Janeiro: Renovar, 2008. p. 197-222. manutenção da atividade empresarial. No que se refere ao campo do direito internacional, tal acepção do princípio da função social mostra-se presente nos tratados internacionais relativos à área de investimentos celebrados entre países, os quais preveem incentivos e proteção equiparada aos níveis nacionais a empresas estrangeiras que fazem investimentos em determinado país.

A segunda vertente oriunda da aplicação do princípio da função social da empresa, que enfatiza a necessidade de submeter o exercício da livre atividade empresarial ao respeito a assuntos de interesse coletivo, tais como direitos trabalhistas, direitos humanos e proteção do meio ambiente, é a que interage de modo mais próximo e direto com o conceito de CER ${ }^{36}$ Contudo, a prática forense revela que, na maioria das vezes, a aplicação de tal vertente do princípio constitucional da função social é realizada de modo a levar apenas em consideração dispositivos do ordenamento jurídico brasileiro e deixando de lado normas e parâmetros oriundos do direito internacional e transnacional, bem como distanciando-se dos pressupostos de uma CER. Porém, a realização de um diálogo entre as ordens brasileira, internacional e transnacional não é, apenas, possível em termos jurídicos, como também é necessária para que empresas possam atuar de maneira responsável.

No que diz respeito ao papel do Estado brasileiro, a interação entre os ordenamentos jurídicos interno, internacional e transnacional possui como base dialógica o princípio constitucional da função social e os Princípios Orientadores para Empresas e Direitos Humanos da Organização das Nações Unidas (Princípios para Empresas e Direitos Humanos). ${ }^{37}$ Ademais, deve-se ressaltar que os Princípios para Empresas e Direitos Humanos, mesmo sendo o produto da consulta entre diversos atores sociais e aprovado pelo Conselho de Direitos Humanos da ONU, não são a priori pertencentes ao campo do direito transnacional, uma vez que eles operam dentro dos limites clássicos do direito internacional. Isto é, os Princípios para Empresas e Direitos Humanos devem ser vistos como uma ferramenta de tradução de instrumentos clássicos do direito interna-

36 PEREZ, Viviane. Função social da empresa: uma proposta de sistematização do conceito. In: ALVES, Alexandre Ferreira de Assumpção; GAMA, Guilherme Calmon Nogueira da (Coord.). Temas de direito civil-empresarial. Rio de Janeiro: Renovar, 2008. p. 197-222. 37 UNITED NATIONS. Protect, respect and remedy: a framework for business and human rights: report of the on the issue of human rights and transnational corporations and other enterprises, John Ruggie. 2008. UN Doc: A/HRC/8/5. 
cional, por exemplo, tratados e convenções de direitos humanos, para a atividade empresarial. Nesse sentido, os Princípios para Empresas e Direitos Humanos requerem que Estados não apenas observem questões relativas a temas relacionados com CER em relações em que o Estado esteja presente, mas também que estes adotem medidas para evitar que empresas abusem de direitos de terceiros, bem como incentivem tais atores a adotarem uma conduta empresarial responsável.

No caso brasileiro, a interação entre os mandamentos constitucionais, tais como o princípio da função social da empresa e a prevalência dos direitos humanos nas relações internacionais, com as diretrizes internacionais, evidencia-se, por exemplo, nos recentes Acordos de Cooperação e Facilitação de Investimentos celebrados pelo Brasil com países como Chile ${ }^{38}$ e Colômbia ${ }^{39}$ que possuem cláusulas estipulando que empresas adotem "princípios e normas voluntárias para uma conduta empresarial responsável". ${ }^{40}$ Assim, em decorrência da redação de tais cláusulas, normas provenientes do direito transnacional, que são caracterizadas pela sua voluntariedade, tais como as regulações privadas transnacionais voltadas ao regramento da atividade empresarial, também passam a integrar o diálogo estabelecido entre os ordenamentos brasileiro e internacional.

Para além de orientar as ações do Estado brasileiro, no que tange à regulação da atividade empresarial, o princípio da função social da empresa, interpretado à luz do conceito de CER, também implica uma mudança na conduta empresarial. A interpretação de tal princípio constitucional, em especial, no que tange sua segunda vertente de aplicação, deve se basear no critério da responsabilidade de respeitar, o qual, além de ser

38 BRASIL. Ministério das Relações Exteriores. Acordo de cooperação e facilitação de investimentos entre a República Federativa do Brasil e a República do Chile. 2015. Disponível em: < http://dai-mre.serpro.gov. $\mathrm{br} /$ atos-internacionais/bilaterais/2015/acordo-de-cooperacao-efacilitacao-de-investimentos-entre-a-republica-federativa-do-brasile-a-republica-do-chile> Acesso em: 07 jul. 2016.

39 BRASIL. Ministério das Relações Exteriores. Acordo de cooperação e facilitação de investimentos entre a República da Colômbia e a República Federativa do Brasil. 2015. Disponível em: <http://dai-mre.serpro. gov.br/atos-internacionais/bilaterais/2015/acordo-de-cooperacaoe-facilitacao-de-investimentos-entre-a-republica-da-colombia-e-arepublica-federativa-do-brasil>. Acesso em: 07 jul. 2016.

40 BRASIL. Ministério das Relações Exteriores. Acordo de cooperação e facilitação de investimentos entre a República da Colômbia e a República Federativa do Brasil. 2015. Disponível em: <http://dai-mre.serpro. gov.br/atos-internacionais/bilaterais/2015/acordo-de-cooperacaoe-facilitacao-de-investimentos-entre-a-republica-da-colombia-e-arepublica-federativa-do-brasil>. Acesso em: 07 jul. 2016. um dos pilares fundantes dos Princípios para Empresas e Direitos Humanos, direciona-se, diretamente, à atividade empresarial. De acordo com as Nações Unidas, a responsabilidade de respeitar das empresas vincula-se ao mínimo com os direitos assegurados na Carta Internacional de Direitos Humanos e nas oito Convenções Núcleo da OIT. ${ }^{41}$ Ademais, empresas são demandadas por tal critério a adotarem políticas e processos de devida diligência (due diligence) a fim de identificarem, prevenirem, mitigarem e quando necessário repararem os impactos negativos causados de maneira direta ou indireta por suas atividades. ${ }^{42}$ Nesse contexto, regras oriundas do direito transnacional passam a desempenhar um papel determinante na regulação da atividade empresarial, uma vez que são elas que estabelecem nos mais determinados setores produtivos os critérios e parâmetros reconhecidos internacionalmente para os processos de devida diligência.

Além disso, no que se refere às interações entre os ordenamentos jurídicos interno, internacional e transnacional, particularmente com base nas normas de direito transnacional relativas aos processos de devida diligência, devem-se ressaltar as orientações adotas pelo Conselho de Direitos Humanos da ONU em junho de 2016: a Guidance to improve corporate accountability and access to judicial remedy for business-related human rights abuses. ${ }^{43} \mathrm{O}$ documento sugere que órgãos de fiscalização (enforcement agencies), bem como o judiciário, ao apreciarem casos relativos a abusos de direitos humanos cometidos por empresas, levem em consideração, ao desempenharem suas funções, as políticas e processos de devida diligência específicos do setor de atuação, em especial aqueles relativos ao local onde tais fatos ocorreram.

41 UNITED NATIONS. Report of the special representative of the secretary: general on the issue of human rights and transnational corporations and other business enterprises, John Ruggie: guiding principles on business and human rights: implementing the United Nations protect, respect and remedy framework. 2011. UN Doc: A/ HRC/17/31.

42 UNITED NATIONS. Report of the special representative of the secretary: general on the issue of human rights and transnational corporations and other business enterprises, John Ruggie: guiding principles on business and human rights: implementing the United Nations protect, respect and remedy framework. 2011. UN Doc: A/ HRC/17/31.

43 UNITED NATIONS. Human rights council: business and human rights: improving accountability and access to remedy. 2016. UN Doc. A /HRC/32/L.19. UNITED NATIONS. Improving accountability and access to remedy for victims of business-related human rights abuse report of the United Nations high commissioner for human rights. Policy Objective 3. 2016. UN Doc. A/HRC/32/19. 
Logo, a fim de demonstrar, de forma concreta, como ocorrem as interações entre normas oriundas dos ordenamentos brasileiro, internacional e transnacional à luz do conceito de conduta empresarial responsável o exemplo do setor agrícola, em especial, a atividade de empresas responsáveis pela plantação de soja será analisado a seguir.

\section{Conduta empresarial responsável e INTERAÇÃO NORMATIVA NO CONTEXTO DA PRODUÇÃO DE SOJA}

O Brasil é um dos maiores produtores de soja do mundo e grande parte da produção é destinada ao mercado exterior. ${ }^{44}$ Dessa forma, torna-se necessário que a produção de tal commodity seja orientada não apenas de acordo com as normativas de direito interno, mas também levando-se em consideração os regramentos oriundos dos direitos internacional e transnacional. Logo, a presente seção, à luz do conceito de CER, demonstra como a interação entre os três ordenamentos jurídicos ocorre no contexto da produção de soja. Contudo, é importante ressaltar que tal exercício será realizado levando em consideração apenas uma das várias fontes normativas de cada um dos ordenamentos jurídicos.

A produção de soja, geralmente, se dá em grandes propriedades e no regime de monocultura, o que não apenas pressiona os ecossistemas onde tal atividade ocorre, mas também os ecossistemas limítrofes e o bioma onde tal atividade é realizada. Logo, a proteção e preservação ao meio ambiente possuem um papel central na especificação dos critérios relativos a uma conduta empresarial responsável no contexto do plantio de soja. Nesse sentido, tal objetivo propicia que a incompletude de cada uma das ordens jurídicas seja minimizada com base em uma maior interação entre as normas de direito brasileiro, internacional e transnacional resultando em critérios mais específicos e adequados visando alcançar maiores níveis de proteção e preservação ambiental.

Por exemplo, a Convenção sobre Diversidade Biológica ${ }^{45}$ lança as bases ao nível internacional sobre medi-

44 EMPRESA BRASILEIRA DE PESQUISA AGROPECUÁRIA. Soja em números: safra 2014/2015. Disponível em: < https://www.embrapa.br/soja/cultivos/soja1/dados-economicos>. Acesso em: 07 jul. 2016.

45 UNITED NATIONS. Convention on biological diversity. UN das para conservação e utilização sustentável de ecossistemas. Nesse sentido, disposições do Código Florestal Brasileiro ${ }^{46}$ determinam que imóveis rurais mantenham áreas com cobertura de vegetação nativa a título de reserva legal, objetivando a "conservação e reabilitação processos ecológicos e promover a conservação da biodiversidade, bem como o abrigo e a proteção de fauna silvestre e da flora nativa". ${ }^{47}$ No mesmo sentido, normas de direito transnacional específicas para a produção de soja, tal como o Padrão RTRS (Round Table on Responsible Soy) de Produção de Soja Responsável determina que produtores de soja possuam um plano de implementação e monitoramento visando a preservação da vegetação nativa e vida silvestre na propriedade. ${ }^{48}$

Contudo, nem sempre a interação normativa entre os ordenamentos brasileiro, internacional e transnacional ocorre de forma complementar e harmônica como no exemplo acima. Muitos são os casos em que as interações entre as ordens jurídicas acabam por gerar conflitos entre dispositivos normativos. No contexto da produção de soja, a partir dos instrumentos analisados, observa-se uma dissância entre os requisitos exigidos, como no caso do direito à liberdade sindical. Empresas envolvidas com a produção de soja que visem ter uma CER de acordo com parâmetros normativos oriundos do direito internacional, tais como os Princípios para Empresas e Direitos Humanos ${ }^{49}$ e as Diretrizes da OCDE,${ }^{50}$ devem respeitar a Convenção no. 87 da OIT

Treaty Series, v. 1760, p. 79. 1992. Available in: <https://treaties. un.org/doc/Publication/CN/1996/CN.29.1996-Eng.pdf> Access: 07 jul. 2016.

46 BRASIL. Lei n. 12.651 de 25 de maio de 2012. Disponível em: <http://www.planalto.gov.br/ccivil_03/_ato20112014/2012/lei/ 112651.htm>. Acesso em: 07 jul. 2016.

47 BRASIL. Lei n. 12.651 de 25 de maio de 2012. Disponível em: <http://www.planalto.gov.br/ccivil_03/_ato20112014/2012/lei/ 112651.htm>. Acesso em: 07 jul. 2016. Artigo 3, inciso III.

48 ROUND TABLE ON RESPONSBILE SOY. RTRS standard for responsible soy production: version 3.0. 2016. Available in: <http:// www.responsiblesoy.org/wpdm-package/english-rtrs-standardresponsible-soy-production-version-3-0/?wpdmdl=11005\&ind $=\mathrm{H}$ SpWNIL91n4Vs8RcZTO1OPd4_KoNqepzJLBM15WD8OHulhbQfAo-91WQpL3QDLFEJrb05QF2lJPWt5Jc04i5nbHigeu5l0W88hAJOkxC-IH9eDMW4EU6dkelpdCLbUlcX5lO12iSr9QUUN-382mH_yBk7sROQmXGJTbnMo8twAuGRgsoaYNBakuI2sgKYde>. Access: 07 jul. 2016.

49 UNITED NATIONS. Report of the special representative of the secretary: general on the issue of human rights and transnational corporations and other business enterprises, John Ruggie: guiding principles on business and human rights: implementing the United Nations protect, respect and remedy framework. 2011. UN Doc: A/ HRC/17/31. Guiding Principle 12.

50 ORGANIZAÇÃO PARA A COOPERAÇÃO E DESEN- 
sobre liberdade sindical e a proteção do direito sindical, que possui o status de convenção núcleo e estabelece que

trabalhadores e as entidades patronais, sem distinção de qualquer espécie, têm o direito, sem autorização prévia, de constituírem organizações da sua escolha, assim como o de se filiarem nessas organizações, com a única condição de se conformarem com os estatutos destas últimas. ${ }^{51}$

O respeito a tal convenção também é demandado por normas de direito transnacional aplicáveis ao setor produtivo de soja, como por exemplo, o Padrão RTRS (Round Table on Responsible Soy) de Produção de Soja Responsável. ${ }^{52}$ Contudo, tais normas encontram-se em conflito com o direito brasileiro, uma vez que, além de o Brasil não ter assinado a Convenção no. 87 da OIT, a Constituição Federal adota o princípio da unidade sindical (art. $8^{\circ}$, II CF/88). Nesse caso, à luz do conceito de conduta empresarial responsável, tal interação entre o direito brasileiro com normas de direito internacional e transnacional acaba por resultar em um conflito.

Uma leitura simplista do conceito de conduta empresarial responsável apontaria para a inexistência de um conflito, uma vez que CER demanda e toma como ponto de partida o respeito e o cumprimento da legislação nacional. Logo, nesse caso prevaleceria o dispositivo constitucional. Contudo, não se pode esquecer que, para além da necessidade de cumprir a legislação nacional ${ }^{53}$, encontra-se no núcleo do conceito de conduta empresarial responsável o segundo pilar fundante dos Princípios para Empresas e Direitos Humanos, qual seja a responsabilidade empresarial de respeitar os direitos assegurados na Carta Internacional de Direitos

VOLVIMENTO ECONÔMICO. Diretrizes da Organização para a Cooperação e Desenvolvimento Econômico para empresas multinacionais. 2011. Disponível em: < http://www.pcn.fazenda.gov.br/ assuntos/ocde/arquivos/2011-diretrizes-da-ocde-para-empresasmultinacionais-pt-br.pdf>. Acesso em: 07 jul. 2016.

51 ORGANIZAÇÃO INTERNACIONAL DO TRABALHO. Convenção n. 87 sobre a liberdade sindical e a proteção do direito sindical. 1948. Disponível em: < http://www.oitbrasil.org.br/content/ liberdade-sindical-e-prote $\% \mathrm{C} 3 \% \mathrm{~A} 7 \% \mathrm{C} 3 \% \mathrm{~A} 3 \mathrm{o}$-ao-direito-de-sindicaliza \%C3\%A7\%C3\%A3o>. Access: 07 jul. 2016. Artigo 2.

52 ROUND TABLE ON RESPONSBILE SOY. RTRS standard for responsible soy production.Version 3.0. 2016. Critério 2.4.1 e Orientação 2.4.1.

53 ORGANIZAÇÃO PARA A COOPERAÇÃO E DESENVOLVIMENTO ECONÔMICO. Diretrizes da Organização para a Cooperação e Desenvolvimento Econômico para empresas multinacionais. 2011. Disponível em: < http://www.pcn.fazenda.gov.br/assuntos/ocde/ arquivos/2011-diretrizes-da-ocde-para-empresas-multinacionais-ptbr.pdf $>$. Acesso em: 07 jul. 2016.
Humanos e nas oito Convenções Núcleo da OIT, que existem de modo independente das obrigações oriundas do direito interno. ${ }^{54}$ Dessa forma, torna-se necessária a realização de um diálogo entre tais normas, como proposto por Jayme ${ }^{55}$ que vise à solução de tal conflito, uma vez que a adoção de um critério de resolução de conflitos que proponha a não observância de uma das normas desse cenário não se mostra adequada.

Porém, é importante frisar que para além de um diálogo normativo a solução de tal conflito perpassa por um outro aspecto central do conceito de CER, qual seja a existência de um processo participativo. Sendo assim, a torna-se necessária a realização de um diálogo envolvendo diversos atores sociais que estejam relacionados com tal cenário, por exemplo, produtores de soja, trabalhadores, sindicatos e representantes do Ministério Público do Trabalho, visando construir uma solução coletiva e sensível as particularidades do cenário no qual incide tal conflito normativo. ${ }^{56} \mathrm{Tal}$ exercício, ainda que não proposto pelo Padrão RTRS (Round Table on Responsible Soy) de Produção de Soja Responsável, é sugerido por outras regulações privadas transnacionais, como é o caso do GoodWeave Standard, ${ }^{57}$ que se concentra em questões relativas ao combate ao trabalho infantil na produção de tapetes. No caso de conflito semelhante, ou seja, da aplicação do standard em países que não ratificaram a Convenção 87 da OIT, a regulação sugere que mecanismos de representação de trabalhadores, tais como grievance cells, sejam criadas por produtores.

Logo, observa-se que, para a solução para os conflitos entre normas de direito interno, internacional e transnacional, não existem alternativas do tipo one siz̨e

54 UNITED NATIONS. Report of the special representative of the secretary: general on the issue of human rights and transnational corporations and other business enterprises, John Ruggie: guiding principles on business and human rights: implementing the United Nations protect, respect and remedy framework. 2011. UN Doc: A/ HRC/17/31. Guiding Principle 11 e 12.

55 JAYME, Erik. Identité culturelle et intégration: le droit international privé postmoderne. Recueil des Cours de l'Académie de Droit International de La Haye, v. 221, n. 9, 1995. Veja também nota de rodapé 28.

56 UNITED NATIONS. Report of the special representative of the secretary: general on the issue of human rights and transnational corporations and other business enterprises, John Ruggie: guiding principles on business and human rights: implementing the United Nations protect, respect and remedy framework. 2011. UN Doc: A/ HRC/17/31.Guiding Principles 3(d) e 18 (b).

57 GOODWEAVE INTERNATIONAL. GoodWeave generic international standard for rug producers. 2016. Available in: <http://www. goodweave.org/standard>. Access: 07 jul. 2016. 
fits all, uma vez que estas são criadas com base em duas formas dialógicas, quais sejam: um diálogo normativo, como já mencionado, bem como um diálogo entre diversos atores sociais envolvidos tendo como base o respeito dos valores fundantes das ordens jurídico-sociais presentes em tal contexto.

\section{Considerações finais}

Ao longo deste artigo, buscou-se explorar as interações entre o direito brasileiro com os direitos internacional e transnacional. Para tal fim, o conceito de conduta empresarial responsável proposto pelas Diretrizes da OCDE foi utilizado como base, uma vez que este tem suas origens e aplicação no campo transnacional, bem como demanda a realização de um contínuo diálogo entre as três ordens jurídicas analisadas. Sendo assim, o presente artigo dedicou-se em suas três primeiras partes a contribuir para com os debates acerca dos conceitos de direito transnacional em Língua Portuguesa, em especial analisando as discussões propostas pela literatura jurídica anglófona, bem como apresentar o conceito de CER, o qual, ainda, não é muito utilizado pela no campo jurídico.

As interações entre os ordenamentos jurídicos brasileiro, internacional e transnacional também foram analisadas tendo como parâmetros conceitos abertos e complementares endereçados a regulação da atividade empresarial, quais sejam a função social da empresa, CER e responsabilidade empresarial de respeitar. Tal análise permitiu concluir, seja em termos teóricos ou práticos, a partir do estudo de caso proposto, que a realização de um diálogo entre as ordens brasileira, internacional e transnacional não é apenas possível em termos jurídicos, mas também necessário a fim que se possa determinar de modo claro e preciso os critérios que embasam a regulação da atividade empresarial responsável.

Dessa forma, verifica-se que é possível a superação de uma interpretação hermética da ideia de função social da empresa, a qual é vigente no contexto brasileiro, à luz do conceito de CER que catalisa a observância de critérios oriundos das ordens internacional e transnacional. Contudo, vale ressaltar, como demonstrado com base no estudo de caso realizado, que o diálogo normativo entre diferentes ordens jurídicas é de natureza complexa, ou seja, apresenta relações complementares e harmônicas, bem como antagônicas e conflituosas. Logo, no que tange à solução de conflitos normativos resultantes das interações entre as ordens jurídicas brasileira, internacional e transnacional à luz do conceito de CER, deve-se ter em mente que não existem soluções prontas, ou seja, torna-se necessária a realização de um amplo diálogo entre diversos atores sociais envolvidos na relação social visando à solução de tal conflito.

\section{ReFERÊnCIAS BIBLIOGRÁFICAS}

ALEMANHA. Deutscher corporate governance kodex. 2015. Available in: <http://www.dcgk.de//files/dcgk/usercontent/en/download/code/2015-05-05_Corporate_ Governance_Code_EN.pdf> Access: 07 jul. 2016.

BENTHAM, Jeremy. The principles of international law. Available in: <http://www.laits.utexas.edu/poltheory/ bentham/pil/index.html>. Access: 07 jul. 2016.

BRASIL. Ministério das Relações Exteriores. Acordo de cooperação e facilitação de investimentos entre a República Federativa do Brasil e a República do Chile. 2015. Disponível em: $<$ http://dai-mre.serpro.gov.br/atos-internacionais/bilaterais/2015/acordo-de-cooperacao-e-facilitacao-deinvestimentos-entre-a-republica-federativa-do-brasil-ea-republica-do-chile> Acesso em: 07 jul. 2016.

BRASIL. Ministério das Relações Exteriores. Acordo de cooperação e facilitação de investimentos entre a República da Colômbia e a República Federativa do Brasil. 2015. Disponível em: $\quad<$ http://dai-mre.serpro.gov.br/atos-internacionais/bilaterais/2015/acordo-de-cooperacao-e-facilitacao-de-investimentos-entre-a-republica-da-colombiae-a-republica-federativa-do-brasil $>$. Acesso em: 07 jul. 2016.

BRASIL. Lei n. 12.651 de 25 de maio de 2012. Disponível em: <http://www.planalto.gov.br/ccivil_03/_ato20112014/2012/lei/112651.htm>. Acesso em: 07 jul. 2016.

CAFAGGI, Fabrizio. New foundations of transnational private regulations. Journal of Law and Society. v. $38 \mathrm{n}$. 1, p. 20-49, mar. 2011.

D'ASPREMONT, Jean. From a pluralisation of international norm-making process to a pluralization of the concept of international law. In: PAUWELYN, Joost; WESSEL, Ramses; WOUTERS, Jan. Informal International Lawmaking. Oxford: Oxford University Press, 2012. p. 185-199. 
EMPRESA BRASILEIRA DE PESQUISA AGROPECUÁRIA. Soja em números: safra 2014/2015. Disponível em: < https://www.embrapa.br/soja/cultivos/soja1/ dados-economicos>. Acesso em: 07 jul. 2016.

FARIA, Tiago Silveira de. A influência do direito desportivo transnacional no ordenamento jurídico brasileiro: da reprodução de normas à aplicação direta pela jurisdição estatal. Revista de Direito Internacional, Brasília, v. 12, n. 2, p. 323-340, dez. 2015.

FINANCIAL STABILITY BOARD. Key standards for sound financial systems. Available in: <http://www.fsb. org/what-we-do/about-the-compendium-of-standards/key_standards/>. Access: 07 jul. 2016.

FORNASIER, Mateus de Oliveira; FERREIRA, Luciano Vaz. A regulação das empresas transnacionais entre as ordens jurídicas estatais e não estatais. Revista de Direito Internacional, Brasília, v. 12, n. 1, p. 395-414, jun. 2015.

GOODWEAVE INTERNATIONAL. GoodWeave generic international standard for rug producers. 2016. Available in: <http://www.goodweave.org/standard>. Access: 07 jul. 2016.

ORGANISATION FOR ECONOMIC CO-OPERATION AND DEVELOPMENT. Principles for corporate governance. 2015. Available in: <http://dx.doi. org/10.1787/9789264236882-en>. Access: 07 jul. 2016.

HALLIDAY, Terence; SHAFFER, Gregory. Transnational legal orders. Cambridge: Cambridge University Press, 2015.

INTERNATIONAL CODE OF CONDUCT ASSOCIATION. The international code of conduct for private security service providers. Available in: < http://www.icoca.ch/ en/the_icoc>. Access: 07 jul. 2016.

JANIS, Mark W. Jeremy Bentham and the fashioning of international law. American Journal of International Law, v. 78, n. 2, p. 405-418, abr. 1984.

JAYME, Erik. Identité culturelle et intégration: le droit international privé postmoderne. Recueil des Cours de l'Académie de Droit International de La Haye, v. 221, n. 9, 1995.

JESSUP, Philip. Transnational Law. New Haven: Yale University Press, 1956.

KANT, Immanuel. À paz, perpetua. São Paulo: L\&PM, 2010.

KIMBERLEY PROCESS CERTIFICATION SCHEME. Kimberley process certification scheme core document. Avai- lable in: <https://www.kimberleyprocess.com/en/ kpcs-core-document>. Access: 07 jul. 2016.

KINGSBURY, Benedict; KIRSCH, Nico; STEWART, Richard. The emergence of global administrative law. Law and Contemporary Problems, v. 68, n. 15, p. 15-61, 2005.

$\mathrm{KOH}$, Harold. Remarks: twenty-first-century international law-making. The Georgetown Law Journal, v. 101, n. 3, p. 725-747, may 2013.

$\mathrm{KOH}$, Harold. Transnational legal process. Nebraska Law Review, v. 75, n. 1, p. 181-207, jan. 1996.

MARQUES, Claudia Lima (Coord.). Diálogo das fontes: do conflito à coordenação de normas do direito brasileiro. São Paulo: Revista dos Tribunais, 2014.

MARQUES, Claudia Lima. Diálogo entre o código de defesa do consumidor e o novo código civil: do 'diálogo das fontes' no combate às cláusulas abusivas. Revista de Direito do Consumidor, São Paulo, v. 45, p. 71-99, 2003.

MORAIS, Dulce Teresinha Barros Mendes de et. al. O papel do direito no contexto do desenvolvimento sustentável: uma avaliação qualitativa de programas corporativos de responsabilidade socioambiental. Revista de Direito Internacional, Brasília, v. 9, n. 3, p. 141-158.

MORIN, Edgar. Ciência com consciência. Rio de Janeiro: Bertrand, 2000.

NIEUWENKAMP, Roel. 2016: CSR is dead! What's next? OECD insights: debate the issues. 2016. Available in: <http://oecdinsights.org/2016/01/22/2016-csr-isdead-whats-next/>. Access: 07 jul. 2016.

NIEUWENKAMP, Roel. Legislation on responsible business conduct must reinforce the wheel, not reinvent it. In: LOVE, Patrick. Debate the issues: investment. Paris: OECD Publishing, 2016. p. 29-33.

NOORTMANN, Math. Transnational law: Philip Jessup's Legacy and Beyond. In: NOORTMANN, Math; REINISCH, August; RYNGAERT, Cedric. Non-state actors in international law. Oxford: Hart Publishing, 2015. p. $57-74$.

ORGANIZAÇÃO INTERNACIONAL DO TRABALHO. Convenção n. 87 sobre a liberdade sindical $e$ a proteção do direito sindical. 1948. Disponível em: < http://www.oitbrasil.org.br/content/liberdade-sindical-e-prote $\% \mathrm{C} 3 \% \mathrm{~A} 7 \% \mathrm{C} 3 \% \mathrm{~A} 3 \mathrm{O}-$ ao-direito-de-sindicaliza\%C3\%A7\%C3\%A3o>. Access: 07 jul. 2016. 
ORGANIZAÇÃO PARA A COOPERAÇÃO E DESENVOLVIMENTO ECONÔMICO. Diretrizes da Organização para a Cooperação e Desenvolvimento Econômico para empresas multinacionais. 2011. Disponível em: < http://www.pcn.fazenda.gov.br/assuntos/ocde/ arquivos/2011-diretrizes-da-ocde-para-empresas-multinacionais-pt-br.pdf>. Acesso em: 07 jul. 2016.

PAUWELYN, Joost; WESSEL, Ramses; WOUTERS, Jan. Informal international lawmaking. Oxford: Oxford University Press, 2012.

PEREZ, Viviane. Função social da empresa: uma proposta de sistematização do conceito. In: ALVES, Alexandre Ferreira de Assumpção; GAMA, Guilherme Calmon Nogueira da (Coord.). Temas de direito civil-empresarial. Rio de Janeiro: Renovar, 2008. p. 197-222.

POSTIGA, Andréa Rocha. A emergência do direito administrativo global como ferramenta de regulação transnacional do investimento estrangeiro direto. Revista de Direito Internacional, Brasília, v. 10, n.1, p. 171-193, 2013.

ROUNDTABLEONRESPONSBILESOY.RTRS standard for responsible soy production: version 3.0. 2016. Available in: <http://www.responsiblesoy.org/wpdm-package/ english-rtrs-standard-responsible-soy-production-version-3-0/? wpdmdl=11005\&ind $=\mathrm{HSpWNIL91n4Vs8R}$ cZTO1OPd4_KoNqepzJLBM15WD8OHulhbQfAo91WQpL3QDLFEJrb05QF21JPWt5Jc04i5nbHi$\begin{array}{llllllllllllllllll}\mathrm{g} & \mathrm{e} & \mathrm{u} & 5 & \mathrm{l} & 0 & \mathrm{~W} & 8 & 8 & \mathrm{~h} & \mathrm{~A} & \mathrm{~J} & \mathrm{O} & \mathrm{k} & \mathrm{x} & \mathrm{C} & -\end{array}$ I H 9 e D M W 4 E U 6 d kelpd CLbUlcX51O12i$\begin{array}{llllllllllllll}\mathrm{S} & \mathrm{r} & 9 & \mathrm{Q} & \mathrm{U} & \mathrm{U} & \mathrm{N} & - & 3 & 8 & 2 & \mathrm{~m} & \mathrm{H} & -\end{array}$ yBk7sROQmXGJTbnMo8twAuGRgsoaYNB-akuI2sgKYde>. Access: 07 jul. 2016.

SANTANA, Héctor Valverde; VIAL, Sophia Martini. Proteção internacional do consumidor e cooperação interjurisdicional. Revista de Direito Internacional, Brasília, v. 13, n. 1, p. 397-418, 2016.

SANTOS, Boaventura de Sousa. Para uma revolução democrática da justiça. Coimbra: Almedina, 2014.

SCOTT, Craig. Transnational law as a proto-concept: three conceptions. German Law Journal, v. 10, n. 7, p. 859-876, jul. 2009

TOMAZETTE, Marlon. Internacionalização do direito além do estado: a nova lex mercatoria e sua aplicação. Revista de Direito Internacional, Brasília, v. 9, n. 4, 2012, p. 93-121.
ENVIRONMENTAL \& social risk policy framework. 2015. Available in: < https://www.ubs.com/ global/en/about_ubs/corporate_responsibility/ how-we-do-business/protecting-people-and-planet/ environmental-and-social-risks/_jcr_content/par/ linklist_0/link_0.2049074265.file/bGluay9wYXRoPS9jb250ZW 50L2RhbS9zdGF0aWMvZ2xvYmFsL2Fib3V0X3Vicy9jb3Jwb3JhdGVfcmVzcG9uc2liaWx pdHkvdWJzLWVzci1mcmFtZXdvcmstdXBkYXRILTIwMTYtZW4ucGRm/ubs-esr-framework-update2016-en.pdf> Access: 07 jul. 2016.

UNITED NATIONS. Convention on biological diversity. UN Treaty Series, v. 1760, p. 79. 1992. Available in: <https://treaties.un.org/doc/Publication/CN/1996/ CN.29.1996-Eng.pdf> Access: 07 jul. 2016.

UNITED NATIONS. Human rights council: business and human rights: improving accountability and access to remedy. 2016. UN Doc. A /HRC/32/L.19.

UNITED NATIONS. Improving accountability and access to remedy for victims of business-related human rights abuse report of the United Nations high commissioner for human rights. Policy Objective 3. 2016. UN Doc. A/HRC/32/19.

UNITED NATIONS. Protect, respect and remedy: a framework for business and human rights: report of the on the issue of human rights and transnational corporations and other enterprises, John Ruggie. 2008. UN Doc: A/HRC/8/5.

UNITED NATIONS. Report of the special representative of the secretary: general on the issue of human rights and transnational corporations and other business enterprises, John Ruggie: guiding principles on business and human rights: implementing the United Nations protect, respect and remedy framework. 2011. UN Doc: A/HRC/17/31.

ZUMBANSEN, Peer. Neither 'public' nor 'private', 'national' nor 'international': Transnational corporate governance from a legal pluralistic perspective. Journal of Law and Society. v. 38 n. 1, p. 50-75, mar. 2011.

ZUMBANSEN, Peer. Transnational private regulatory governance: ambiguities of public authority and private power. Osgoode CLPE Research Paper Series, Toronto, v. 8, n. 10, p. 1-38, 2012. 
Para publicar na Revista de Direito Internacional, acesse o endereço eletrônico www.rdi.uniceub.br ou www.brazilianjournal.org.

Observe as normas de publicação, para facilitar e agilizar o trabalho de edição. 